\title{
LINDY OSBORNE
}

\section{WHAT WORKS? EMERGING ISSUES}

\author{
INTRODUCTION: EMERGING LEARNING ENVIRONMENTS FOR \\ ARCHITECTURAL EDUCATION
}

Diversification and expansion of global higher education in the 21 st century has resulted in learning environments in architectural education that can no longer be sustained by the Beaux-Arts Atelier model. Budgetary pressures, surging student numbers, extensions to traditional curricula, evolving competency standards and accreditation requirements, and modified geographical and pedagogical boundaries are pointing a spotlight on the need for a review of the design of learning environments in the higher education context. The Architects Accreditation Council of Australia [AACA] course accreditation requirements dictate a 1:17 minimum staff/student teaching ratio as well as some aspects of space provision. Unsustainable specifications are driving the need to review pedagogical practices.

The influx of new digital technologies and largely ubiquitous access to affordable Wi-Fi-enabled mobile devices has helped to democratise knowledge and is transforming when, where and how students learn; and this is having an impact on the types of spaces required to support effective learning. The traditional lecture theatre, with the teacher as sole conveyor of knowledge, is graciously now becoming a memory of the past. More efficient design of space that responds to this digital (r)evolution, has the potential to contribute significantly to savings in provision and management of learning environments.

Although many studies globally, and particularly those in the United Kingdom, have examined learning environment design, few studies have focussed specifically on the design of studio learning environments or the design of these environments for architectural education, especially in Australia. While facing comparable changes and pressures, architecture continues to be taught in similar environments using similar pedagogical approaches to those first developed when it moved from an apprenticeship model to national higher education systems in the early nineteenth century at the École des Beaux Arts (Kostof, 1977). This chapter contextualises previous research in this area and provides additional insight into the emerging issues in the design of learning environments for architectural education in Australia. Using a grounded theory and thematic analysis mixed methodology, data obtained over a three-year period were interpreted to understand the significant relationships between spatial, technological and pedagogical contexts and the impact that these have on teaching architecture students and preparing them for professional practice.

While definitions vary, in this chapter, 'learning environments' refers to the spatial, technological, social and pedagogical contexts within which learning occurs and which have an impact on student engagement, achievement and attitude. The description includes physical learning environments, blended and virtual environments, spaces and places, and on-campus and off-campus formal and informal environments. 


\section{LITERATURE REVIEW: THE FUTURE OF ARCHITECTURAL DESIGN STUDIO TEACHING AND LEARNING IN A NEW DIGITAL WORLD}

\section{The spatial context of learning architecture in Australia}

One of the most significant assets of a university is physical space. In Australia the capital and operating expenditure represents about $20 \%$ of the average higher education institution's operating costs. Coupled with increasing competition for students and government funding, the provision of suitable space is becoming a high priority for universities (TEFMA, 2009). In his literature review on the learning spaces for the 21 st century, Temple notes with disappointment that conventional texts on teaching and learning in higher education "do not mention the nature of learning spaces, even in passing". (2007, p.10)

The whole landscape of spatial design and use is currently undergoing significant change. Harrison and Hutton describe it as "the hybridising of space, the dispersing of work, the annexing of non-traditional spaces or the freedoms and constrictions that come with new technology and the blending and layering of virtual and physical work arenas" (2013, pp. viii/1). The design of learning environments provides a great opportunity to lead the way into these new hybrid territories. Lifelong learning takes place in a multiplicity of spatial environments, both formal and informal, and is accessed through physical, virtual and hybrid communities. This rapidly evolving landscape includes purpose-built educational institutions as well as incidental spaces like galleries, conference centres, or the headquarters of professional bodies (Harrison \& Hutton, 2013).

Reviews across the UK have revealed inefficient utilisation of higher education teaching spaces during core learning hours (Neary et al., 2010). The Australian Tertiary Education Facilities Management Association (TEFMA) reports that in order to achieve efficient space management and plan for future requirements, we need to better understand the current standards and benchmarks and utilise planning models to measure how well space is being used (2009). TEFMA's space planning guidelines have been specifically developed for this purpose. They provide useful space planning tools which help to ensure effective, efficient and economical use of space that responds to the space requirements of institutions.

The TEFMA standards recommend that an appropriate targeted utilisation for architectural design studios in Australia is 56\%. The targeted room frequency and occupancy are at $75 \%$ each, based on a typical overall week of 67.5 hours [8.00am9.30pm, 5 days/week] (TEFMA, 2009). It is interesting to note TEFMA's recommended design standards for allocation of UFA per student learning in an architectural design studio context. While it is $2.8 \mathrm{~m}^{2}$ for 1 st year students, it drops down to only $2.2 \mathrm{~m}^{2}$ for more senior students (TEFMA, 2009). TEFMA also provides recommendations for the amount of dedicated faculty/department/discipline space typically required for different users. This is separately recorded from the central pool of timetabled spaces. At the department level, spaces vary significantly. For example, only $1 \mathrm{~m}^{2}$ UFA/EFTSL is recommended for accounting, business management and economics students (who 
typically spend most of their time learning in generic spaces), while space provision for dental studies and veterinary science students (who are typically learning in specialist 'wet laboratory' type spaces), ranges from $16-18 \mathrm{~m}^{2}$ UFA/EFTSL. By comparison, the recommended UFA/EFTSL for architecture students is $8 \mathrm{~m}^{2}$ (TEFMA, 2009), which is an increase on the 2002 reported data of $6 \mathrm{~m}^{2}$.

Dedicated faculty/department/discipline recommendations average at $46.8 \%$ of total campus space provision, with $5.2 \mathrm{~m}^{2}$ UFA/EFTSL, campus-wide. This is significant compared to centrally timetabled teaching spaces (lecture theatres, seminar and tutorial rooms), which only average at $9.4 \%$ of total campus space provision, with $0.93 \mathrm{~m}^{2} \mathrm{UFA} / \mathrm{EFTSL}$, campus-wide. Interestingly, library space is comparable at $8.5 \%$ of total campus space provision, with $0.91 \mathrm{~m}^{2}$ UFA/EFTSL, campus-wide, and commercial space is not far behind at $4.81 \%$ of total campus space provision, with $0.51 \mathrm{~m}^{2}$ UFA/EFTSL (TEFMA, 2009). With the combined spatial provision of centrally timetabled teaching spaces, library spaces and commercial spaces averaging less than half of the spatial provision of dedicated faculty/department/discipline spaces, the importance of the provision of dedicated and specialist spaces is clearly evident. This is interesting to note in the context of current learning environment research which tends to focus on better understanding generic, rather than specialist learning environments.

TEFMA reports that a new concept emerging from recent University Master Planning in Australia is a move towards smaller cafés and outdoor eating areas: "These areas also provide for informal meeting space and the introduction of wireless technology also enhances the use of these spaces for both staff and students" (TEFMA, 2009, pp.14). They recommend that external cafeteria eating spaces that double as informal learning environments can be setup at $2-3 \mathrm{~m}^{2}$ UFA/EFTSL. It is interesting to note that this is much the same as their recommended standards for students learning in an architectural design studio context.

\section{The social context of learning}

Jamieson argues that university campuses have been shaped historically by traditional pedagogical approaches and the classrooms required to support these. He defines informal learning as:

course-related activity undertaken individually and collaboratively on campus that occurs outside the classroom and does not directly involve the classroom teacher. Informal learning is generally viewed as those 'other' activities students do to learn between formal classes, including course reading, class preparation, and assignments and project activity (Jamieson 2009, pp. 19).

As informal learning has not been considered a serious matter in the past, universities have not committed significant resources to understanding and developing this pedagogical concept. However, attitudes and the balance of formal 
and informal settings are now changing as students are required to learn in a more self-directed manner. Jamieson believes that "the future campus will be determined by the university's response to informal learning" (2009, pp. 19).

William Mitchell, a professor of architecture and media arts and science, led the Smart Cities research group at the M.I.T. Media Lab. At a presentation at the M.I.T in 2004, he argued that the forms and functions of future learning environments would change rapidly to accommodate computer and communication technologies as architects discovered new ways to take advantage of them. He speculated that if new types of learning environments incorporated new technologies, they might also create new patterns of social and intellectual interaction. This would have an impact on the demand for physical space on campuses and suggest new approaches to overall campus design strategies, enabling the whole campus precinct to become an interactive learning device. He believed that all campus space (both formal and informal) with Wi-Fi accessibility should be considered as a potential ad-hoc classroom environment (Harrison \& Hutton, 2013).

Oblinger (2005) asserted that a key learner-centered principle is that learning is social. Social learning requires student interaction, and therefore learning spaces should enable students to establish mutual relationships, engage in rigorous discussions, work collaboratively on group assignments and present or teach their learning outcomes in a public context (Oblinger, 2005). Mobile devices with Wi-Fi capability have now completely transformed the educational world. Students have turned nomadic (Alexander, 2004), accessing information and collaborating with each other outside traditional campus spaces and places. The impact that these new digital technologies have on learning spaces is summarised by Oblinger, who argues that the definition of a classroom has transformed from one that was once defined by the class to one that is defined by learning:

The Internet has changed notions of place, time, and space. Space is no longer just physical, it incorporates the virtual. New methods of teaching and learning, based on an improved understanding of cognition, have emerged, as well. (2005, p. 14)

In their University of Buffalo Master Planning case study, Dugdale et al. (2007) argued for the incorporation of 'Hub Concepts' to respond to user needs and aspirations about future pedagogy and concepts for exemplary social learning spaces. The concepts addressed the needs of three sets of constituents: the 'Teaching Hub' that contained clusters of experimental classrooms with academic technology support; 'Learning Corridors' that enriched the student realm by enhancing paths and circulation spaces near classroom activity; and the 'Faculty Hub' - a shared destination for interdisciplinary groups to meet and collaborate (2007). Jamieson (2009) also asserted that social hubs and internal student 'streets' within buildings that featured a mix of functions were the key features of campus life and supportively promoted both social and learning-related activities. 


\section{The design of studio environments}

The design studio has been considered the primary context for design learning since it originated from the École des Beaux Arts in the early nineteenth century. Schön (1983) proclaimed that the main purpose of the design studio was to 'coach artistry' by operating as an environment where students are inducted into the 'master mysteries' through collaborative dialogue with their studio teacher who assists in shifting them into 'disciplinary norms'. What is it about the design studio environment that has made it so special for the past 200 years and how does it need to adapt in order to keep pace with new pedagogical theories and approaches?

There is growing evidence that today's architecture students no longer do significant work in their institution-provided design studio spaces. This is having an impact on the positive tradition of students working together in a collective environment and learning from each other and teaching staff as the need arises. These spaces are often insufficient in quantity and deficit in quality. Student complaints include "poor storage facilities for both work and personal belongings, inadequate (or non-existent) technology provision, insufficient pin-up space, poor atmosphere and lack of companionship" (Duggan, 2004, p.72).

Furniture is often poorly maintained and inappropriate in supporting changing learning needs that include group and individual work, group crits and social learning opportunities. Similarly, inappropriate, or a lack of, technology is providing some barriers to students regularly using their studios spaces. As personal technology is becoming more accessible, affordable and mobile for students, their needs are changing. They no longer need the basic provision of desktop computers, but rather, they need access to specialist equipment and software, printing services [both 2D and 3D] and appropriate technical support. These resources are not typically located within design studio environments, most of which are described as technologically deprived. Duggan (2004) argues that, "greater student mobility accompanied by more complex juggling of both student and institutional priorities, more concentrated teaching days, poor quality studio provision and greater student reliance on technology, has resulted in the pattern of studio use shifting from live-in to drop-in, and the nature of studio identity being increasingly forged by events rather than space" (p. 73).

However, even if spaces were re-appropriated to encourage better student attendance, the current design studio educational model is still problematic. While students may appear to be working adjacent to each other, they are still typically working in isolation, often hiding their key ideas from each other and competing for the attention of the teaching staff. This is at odds with how they will be expected to work once they are in practice. Architects, even if working as sole practitioners on very small projects, never work completely independently. The act of designing and constructing a building is dependent on multiple people with different areas of expertise collaboratively contributing to its creation, and the architect is typically the party responsible for coordinating all of the works. However, current accreditation and institutional requirements uphold the "primacy 
of the autonomous designer by focusing all its attention on the student's experience as an individual" (Cuff, 1991, p. 81).

In a design studio educational context, group work tends to be focussed around the beginning stages of design (for example precedent research and site analysis), while the design and documentations stages tend to be limited to individual contributions. This is because individual learning is a crucial requirement for current design studio education models. However, in professional practice, the contributions of other team members including other architects, consultants, and of course clients and end-users are of critical value throughout the design process (Koch et al., 2002). Simultaneously teaching both individual and collaborative work skills is an unsolved challenge in the design studio context, and more experimental research must be done in this area.

\section{Signature pedagogies and learning to become Architects}

Today's learners cannot be classified as a 'typical group' of high school leavers with generic learning styles and needs. They are juggling a multiplicity of different commitments, and their learning needs are rapidly changing. Mature aged students with competing time priorities cannot be defined simplistically and they are becoming increasingly common in the Australian higher education sector. In order to remain competitive, Australian universities need to address global issues and ensure that they are offering courses that are relevant and accessible to a variety of diverse learners.

Shulman's theory of 'signature pedagogies' (2005) offers a helpful way of describing the social nature of design learning and how design studio practices may come into conflict with pedagogical practices imported from different disciplines. Signature pedagogies are ways of teaching and learning situated in the professions (such as law, medicine and architecture) and which specifically focus on teaching students how to become practicing members of the profession. There is a direct connection between professional practice and the activities undertaken in the learning environment (Shreeve, 2012).

Significant past research has systematically pointed to the success of, and student's preference to, engage in an active learning strategy (Barr \& Tagg, 1995; Bonwell \& Eison, 1991; Jamieson et al., 2000). Active learning is a straightforward learner-centred principle. Typically, real-world problems are proposed and through these, learners practice their responses in a safe environment while receiving feedback from their peers and teachers. Students are required to be actively involved in their learning while engaging in higher-order thinking tasks such as analysis, synthesis, and evaluation. In order for students to successfully engage in active learning, instructional activities need to be aligned to support students to learn through doing (or observing), followed by thinking about what they are doing (or observing) through dialogue with themselves or others (Bonwell \& Eison, 1991). The physical environment plays an important role in enabling learners to participate in the active learning activities (Osborne et al., 2012) which may include items such as interacting with people and information from outside the 
classroom, or engaging in simulation, virtual field trips, role playing, etcetera (Oblinger, 2005).

Transforming and extending the notion of active learning, more recent literature is now exploring the theories of connected learning (Nussbaum-Beach \& Hall, 2012). Connected learning promotes learning that is humanitarian or socially focussed and driven by learner's interests or passions. These are then linked to academic achievement, career success or civic engagement (Ito et al., 2013). This new transformative approach takes advantage of the opportunities afforded to students who are operating in a constantly changing and 24/7 connected digital world. A key principle is that three critical spheres of learning are connected: academics' strengths, a learner's interests, and inspiring mentors/peers. In addition to this, the emerging digital innovations of new media and the connected age are exploited, and the concept that making and creating lead to deeper learning and understanding is deployed in classroom practice.

Connected learning encourages students to "experiment, to be hands-on, and to be active and entrepreneurial in their learning, recognising that this is what is now needed to be successful in work and in life," "What is connected learning," 2014). As evidenced by Mewburn (2012), the design studio is a flexible model of teaching that can encompass a range of teaching and learning approaches. Design studio practice can indeed differ from Schön's model of 'coaching artistry' and embrace a range of different and less traditional configurations.

\section{Emerging architectural learning environment design and new pedagogical approaches}

Considering the contextual issues discussed above, a significant issue arising is how to forecast the design of future learning environments for architectural education. In the past this area of research attracted interest, for example Schön, in 1983, however, little recent research has specifically addressed the evolving physical and pedagogical design of architectural studio learning environments which are the primary conduit of architectural education.

This chapter describes two recent studies conducted at a major Australian University. It had two major purposes: to identify the emerging trends in the design of future learning environments for architectural education in Australia; and to understand and describe spaces in which students of architecture are likely to learn in the future. The research explored the important linkages between space, technology, pedagogy and context using a multi-methodological qualitative research approach. By understanding and aligning these emerging trends with current dynamic technological, social and global changes in how architects are now practicing architecture, this chapter suggests a new pedagogy, exploring how students of architecture are likely to learn in the future.

Active and connected learning environments support dynamic project-based and collaborative learning models which have recently become more common in disciplines outside design and the arts. It is anticipated that they may have a 
positive impact on, and important contribution beyond, the architectural design studio learning environment.

\section{Study 1: Technology enabled learning spaces, SCALED-UP}

Learning environment design, technology and pedagogical approaches. In the first study, a new digital learning laboratory was designed and constructed as a prototype learning environment for a new Science and Technology Precinct and Community Hub. This space adapted Student-Centred Active Learning Environment for Undergraduate Programs (SCALE-UP) principles and sought to address the specific requirements of the various case study users. SCALE-UP learning environments are designed to support a studio-style pedagogical approach and promote the facilitation of desired interactions between students. The environment is purposefully designed to be a "highly collaborative, hands-on, computer-rich, interactive learning environment for large-enrolment courses" (Beichner \& Saul, 2003, pp.01). Classes are designed to include hands-on activities, simulations and role-playing, and student learning is primarily hypothesis or problem-based learning driven. Students are required to sit in three groups of three students at separate tables, whilst teachers circulate the room, engaging with teams or individuals, as the need arises (Beichner \& Saul, 2003).

The design requirements for the prototype space varied extensively, as it was designed to be used by a variety of different stakeholders, including those from science, the humanities, business and design. In advance of the construction, the architects and planning team consulted the users of the nominated case-study, to ensure that all envisioned pedagogical and curriculum needs were addressed and accommodated for in the proposed design. Due to the diversity of requirements and time and budgetary restrictions, a 'best-case' design scenario was agreed upon and signed off for construction.

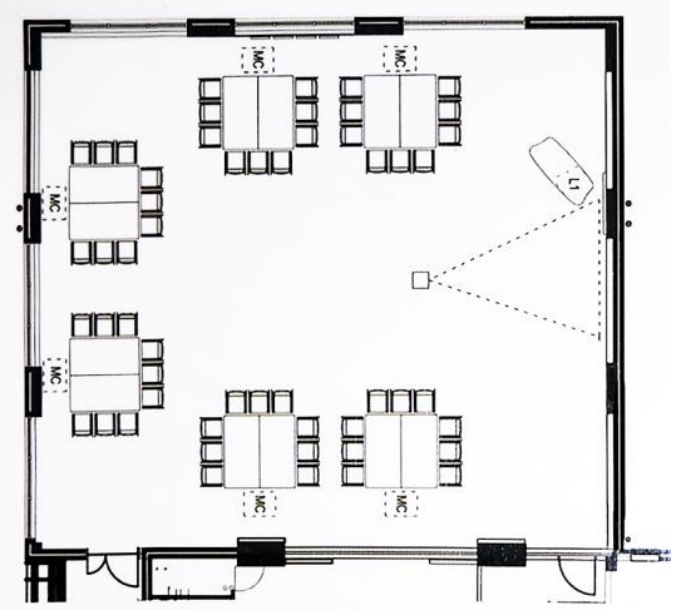




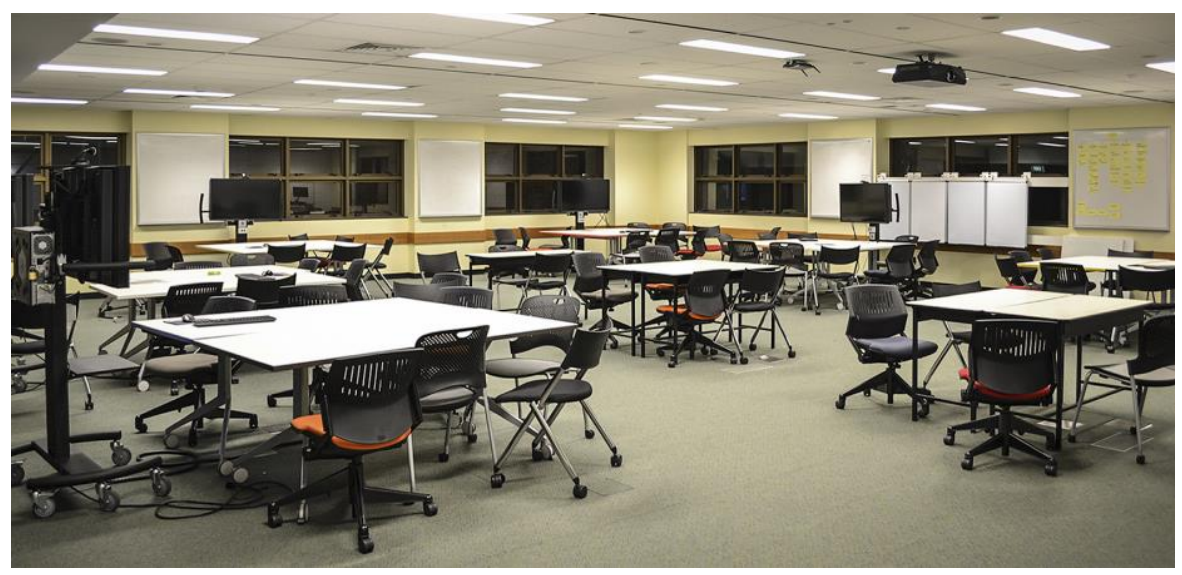

Figure 1. Floor plan and photograph of study 1 learning environment. Photo credit: Lindy Osborne.

The arrangement of space allowed for 54 students working in six distinct group work zones, a central open space, a semi-mobile media equipped lecture podium and a laptop garage which contained 10 laptops, six USB document cameras and two mobile teaching headsets. Each of the six group work zones consisted of two mobile tables, nine mobile chairs and one large mobile computer. The work zones were each orientated to face an outside wall. Sufficient power outlets were provided in floor boxes to allow all students access if required.

In addition to $\mathrm{Wi}-\mathrm{Fi}$ access, the mobile computers were loaded with the following web-based software to help to facilitate a digitally collaborative learning environment: Skype (video calling and instant messaging application, with mobile device integration); Advanced Video Conferencing (EVO) (video conferencing tool that facilitates online meetings for up to 16 participants); Net Support School (class-room management application, to allow central control all class computers); Open Web Lecture (OWL) (student response system facilitated through mobile devices); Google Docs and Mindmeister (applications for collaborative 'real time' creation, editing and sharing of documents/mind-maps); and Social Media (social utilities that connect users). 
Data collection and analysis. 165 second year architecture students selfallocated into two different design studios. $70 \%$ of the students chose to continue working in their traditional design studio environment and the other $30 \%$ chose to participate in this study, which involved taking their classes in the new prototype SCALE-UP learning environment. All the architecture students attended the same information sessions, followed the same studio curriculum and completed the same pieces of assessment; the only significant differences were the allocation of teaching support staff and the physical environments within which the studios were conducted.

At the end of the semester, the teaching support staff and students completed a questionnaire about their experiences of teaching or learning, in their respective learning environment. The questionnaire responses reflected data from $100 \%$ of the 10 teaching staff and over $70 \%$ of the student cohort. In addition to the questionnaire, the teaching support staff and students were also invited to attend focus groups where a synergistic approach allowed participants to clarify and expand upon their experiences of teaching or learning architectural design within the traditional and/or new experimental settings.

Using a mixed methodology of thematic analysis and grounded theory, the questionnaire and survey data were coded, extrapolated, compared, contrasted and finally merged, to reveal six distinct emerging themes which were instrumental in causing resistance or influencing adaptation to the new SCALE-UP learning environment (Osborne et al., 2011).

\section{Study 2: New studio spaces, based on designs from study 1}

Learning environment design, technology and pedagogical approaches. Following the completion of Study 1, the traditional architectural design studios were redesigned and renovated taking cues from the lessons learned in the first study and again adapting SCALE-UP design principles. These were the studios in which the 'other' $70 \%$ of students in Study 1 had originally chosen to learn. The renovations, however, were also required to respond to the heritage protected requirements of the building and a more limited budget, so not all "ideals" could be incorporated because of these limitations. Similar to Study 1, the renovations included modifications to the spatial environment (limited because of the aforementioned heritage protection of the building) and the addition of new technologies and furniture provided within these spaces. 

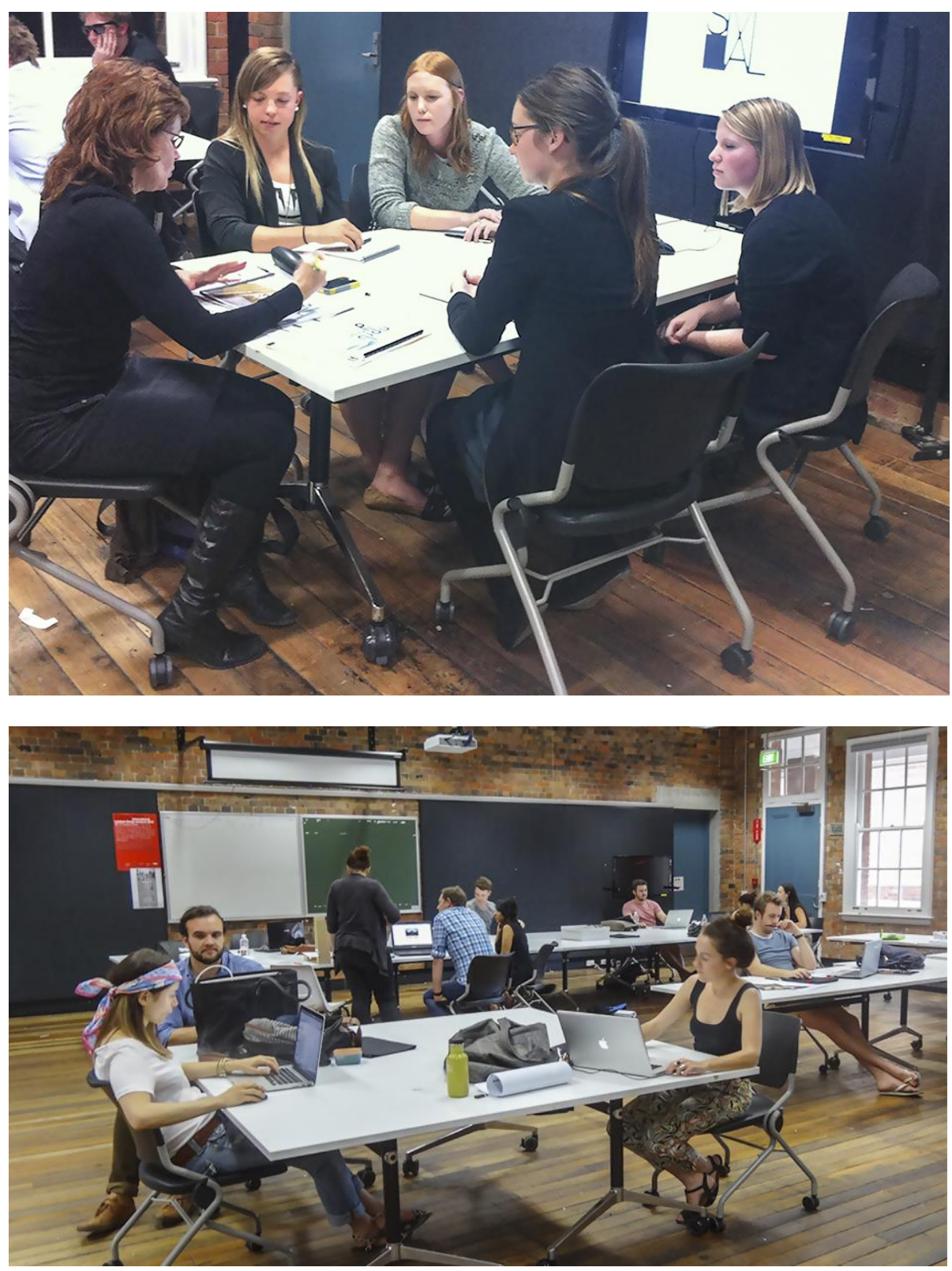

Figure 2. Photographs of study 2 learning environments.

Photo credit: Lindy Osborne. 
The spatial changes included the somewhat bold decision to merge six smaller, separate studios into four larger combined studio spaces through the demolition of internal dividing partitions. By further opening up these spaces it was believed that new pedagogical opportunities, for example team and larger class teaching, could be explored and facilitated. The total occupancy capacity of the combined studio spaces was 108 students: 18 students in each of the two smaller studios and 36 students in each of the two larger studios. In addition to the studio space reconfiguration, old carpets were removed to reveal the original heritage listed timber floorboards.

Technology additions included six new fixed data projectors and screens (one per 18 students), 12 new large mobile computers (one per nine students), and multiple mobile pin-boards and whiteboards. While not as prescriptive as Study 1, the spatial layout and arrangement of each designated studio space was intended to consist of distinct group work zones around an open central space, supported by a data projector and screen, and the mobile computers. The new furniture selected included large white tables and chairs that were both mobile and stackable. These tables were configured in sets of two to seat groups of 9 students and were orientated to face the outside wall like those in Study 1. In addition to Wi-Fi access, the mobile computers hosted software to provide scaffolding to the collaborative learning environment, although this was not as sophisticated at the software provisions of Study 1. Software included: Skype; Google Docs and Mindmeister; and Social Media.

Like in Study 1, it was intended that teachers would take advantage of SCALEUP principles when utilising these spaces. As architectural design studios were mainly taught in these spaces, a studio-style pedagogical approach was almost universally implemented. This included student driven hands-on learning by making or drawing activities, role playing and problem based learning. Many of these activities were enacted collaboratively while the teacher moved around the classroom to check on the progress of individuals or groups and provide helpful disruption, where required. The new environment and embedded technology helped to facilitate a highly collaborative and interactive learning environment with important web connectivity for information sourcing or sharing.

Data collection and analysis. During Study 1, 79 second-year architecture students (approximately $70 \%$ of the students) completed a questionnaire about their learning experiences in the traditional architectural design studios. Study 2 was expanded to include questionnaire responses from 356 students from all five years of the undergraduate and the masters courses; approximately $40 \%$ of all enrolled architecture students. These students had all experienced learning in the newly renovated architectural design studios, prior to completing the Study 2 questionnaire.

Again, using a dual method qualitative approach, the questionnaire data were coded and extrapolated using both thematic analysis and grounded theory methodology. The results from these two studies across two consecutive years were compared, contrasted and combined to reveal five distinct emerging thematic 
areas that were instrumental in influencing adaptation to the newly renovated architectural design studio learning environments. These five thematic areas highlighted the important linkages between Space, Pedagogy and Technology in supporting the students' overall learning experience (Osborne et al., 2012).

\section{FINDINGS}

The results of these two studies were, in some ways, surprising. A key over-riding theme was the strong resistance by students when adapting to learning in the new high technology-embedded learning environments. However, notwithstanding the surprising extent of this resistance, three quarters of the students agreed that their overall learning experience in the newly renovated studios had been positively enhanced, despite the perceived disruptions. Other key themes were the importance of the learning spaces, furniture, and technologies in the design of the physical environment required to support effective blended student learning.

\section{Resistance in adaptation}

Six distinct themes that address proficiency, support and compatibility and which were instrumental in offering resistance or influencing adaptation to the newly renovated, high technology-embedded learning environments were identified by Osborne et al. (2011), and are summarised below:

- Technical/technological proficiency: Training with respect the use of the new technologies and equipment must be supplied for teachers and teaching support staff; this knowledge can then be passed on to students.

- Technological infrastructure support: The provision of generic technological equipment and software can provide limitations when there is a large range of different users with specialised requirements, sharing the same facilities.

- Human infrastructure support: Institutions should consider appointing a dedicated person to support the specific technology and learning environment needs.

- Pedagogy/technology compatibility: In a design studio, digital technologies support the research, collaboration and presentation stages of the design process, however they can provide limitations too, especially when the users are lacking in skills and competence.

- Pedagogy/technology/environmental compatibility: While SCALE-UP learning environments support self-directed and collaborative group work, it is still important to retain some elements that support traditional design education.

- Pedagogy/environmental compatibility: The relationship between amenity and learning is of significance: the physical size, cleanliness and perceptions of value invested in the space, for example furnishings, may impact on how a student engages with their learning. 


\section{Spatial elements, technology and furniture}

While there was a generally positive response to the improved amenity of the renovated learning environments, some issues arose as a result of the changes. The two studies resulted in five distinct thematic issues which centred around spatial elements, new and traditional technologies and the impact of furniture selection embedded within these spaces (Osborne et al., 2012). These issues are summarised thematically, below:

- 1 -- Social learning spaces: Over $90 \%$ of students responded positively to the addition of more social and informal learning spaces to the campus environment. When asked where their favourite space to work was, the students' first preference was the architectural design studios, and following these, students nominated various alternative social spaces such as the collaborative and informal breakout spaces in the campus library, coffee shops, and the unstructured design student common rooms. In all these spaces learning is selfmanaged and, with the simple addition of Wi-Fi access and mobile technologies, students can easily access online resources, share information and collaborate without the intervention of a teacher.

- 2 -- Sensory (dis)abilities: Two sensory items were identified as potential barriers to learning in the new high technology-embedded environments acoustics and vision. The elimination of the internal dividing partitions to provide a larger and more flexible space, in combination with the removal of the carpeted floor finish negatively impacted the acoustic properties of the space. Students reported difficulty in hearing as a result of peripheral noise, which impacted on their ability to concentrate and learn. Students' vision was also negatively impacted - spaces were redesigned to eliminate the notions of a 'front' or 'back' of the classroom, but rather provide a more equitable collaborative learning experience. However, reliance on using technology (mobile computers) to demonstrate ideas or explain concepts was problematic for some students who reported not being able to see properly. Cultural conditioning leads students to believe that effective learning occurs best in a quiet and small, enclosed space - this is an important issue that must be addressed when teaching in large open plan collaborative spaces.

- 3 -- New Technologies: The introduction of new technologies, including data projectors, and mobile computers, was one of the most significant changes to the redesign of the architectural studios. The data showed a notable increase in students' beliefs that technology improved their learning; just over one third of students believing this in Study 1, increasing to nearly two thirds, in Study 2. The introduction of new technologies allowed more flexibility with how student project work was presented and shared. This is of particular importance during the student 'crit'- a signature pedagogy of design studios. Students believed that the introduction of new technologies had a positive impact on and assisted them with, group-work, collaboration, sharing and communication of their ideas.

- 4 -- Traditional Technologies: A trend that emerged across the two studies was how quickly students moved away from their reliance on pin-boards and whiteboards, to become more comfortable using new technologies to display 
their work. The study indicated a $10 \%$ increase in students bringing their own mobile devices to class, and a 33\% reduction in their reliance on pin-boards and whiteboards. Junior students generally learn to draw by hand, but as their skills and confidence build they transition to working in a more digital domain, including both Computer Aided Design drawings and digital scans of freehand conceptual sketches. Teaching staff often insist on printed copies of drawings for a 'crit' pin-up, to allow the work to be viewed as a whole rather than consecutive series of images shown through a digital medium.

- 5 -- Furniture: A significant component of the design studio renovation was for all furniture to be mobile and stackable to allow users to take ownership of the space and easily transform it to suit their pedagogical needs. A further requirement was to provide large-scale tables with white surfaces to allow for production and display of architectural drawings. $80 \%$ of the students described the positive impact that the new furniture had on supporting collaborative learning - a signature pedagogy of the design studio.

\section{CONCLUSION}

When planning the design of new or significantly modified learning environments, it is essential to approach this task through multiple lenses. Consideration must be given to the spatial, technological, and social and pedagogical contexts within which learning take place, as each of these has an impact on student engagement, attitude, and ultimately achievement. While focus tends to be given to the design of physical spaces and places for teaching, it is also important to consider learning that occurs in virtual and informal environments, both on and off campus, and to understand how key components of these can be positively supported in considered design of space.

\section{Spatial context}

The relationship between amenity and learning is of significance: the physical size, cleanliness and perceptions of value invested in the space may impact on how a student engages with their learning. When designing open-plan and collaborative design studio environments, careful consideration must be given to the implications that they have on students' ability to hear and see effectively. While some of these issues may be simply attributed to cultural conditioning when adapting to a new environment, if a student cannot hear or see effectively, learning may well be diminished. Flexibility and appropriateness of furniture selected is important, and consideration should also be given to the amount of furniture provided, particularly if varying pedagogical modes of learning may take place, in the same space. Where time allows, it is beneficial to trial different types of furniture and collate feedback from the users prior to expending large amounts of funds on what may well become redundant selections. 


\section{Technological context}

While there is still a romantic yearning for the placement of old technologies in architecture design studio learning environments, there is evidence of a swing away from these, and towards the use of new, digital technologies. It is also evident, however, that the new cannot simply replace the old, and that the provision of blended old and new technologies appears to be most successful solution at this stage, while student and lecturer confidence/competence, is built. Transitioning to learning and teaching in high technology embedded learning environments can be problematic at first, and must be supported by a number of factors. Teachers need ongoing training to use new technologies and equipment, and regular maintenance of the equipment is required. Institutions should consider appointing a dedicated person to support technology and learning environment needs. Rather than attempting to satisfy all users with establishing generic spaces, it is advisable to provide discipline or faculty specific environments, where specialised technological requirements can be satisfied.

\section{Social and pedagogical context}

Student desire for more social and informal learning environments is clearly evident. While it is not appropriate to simply abandon the traditional teachercentred learning environments that still have their place in university education, there are some components of informal or social learning pedagogical approaches that may well be introduced in learner-centred collaborative blended learning environments. Teachers must not rely on digital technologies alone, especially when teaching junior design students. While technologies support the research, collaboration and presentation stages of the design process, they have limitations. It is important to maintain a blended approach, and to maintain the importance of hand drawing/modelling and representation ideas. For the time being at least, it is still important to retain some elements that support traditional design education, for example the provision of pin-boards, drafting tables, light tables and physical model making equipment.

While the results of this overall study are somewhat varied and indicate both areas in need of improvement and areas which have been improved, arguably the most important results from this study indicated that students believed that their overall learning experience had been positively enhanced as a result of the renovations of the architectural design studio learning environments. Having three quarters of students state they had a positive overall learning experience in the renovated studios confirmed the importance of the design of the physical environment in supporting blended student learning. This is significant as we transition towards more teaching and learning in blended and online environments.

\section{IMPLICATIONS FOR TEACHERS AND DESIGNERS}

Design studios exemplify active and connected learning environments. They support dynamic, project-based, collaborative and connected learning models. 
While the studies in this chapter took place in an architectural design studio setting, it is anticipated that the implications of this research may well have a positive impact beyond the confines of design education, as many similar settings also exist outside of the design studio. The findings are not only significant in alternative higher education settings, for example the arts or humanities, but arguably they may also be of benefit in secondary and primary education settings, where similar approaches are being experimented with.

Architectural practice is undergoing significant change globally, and architectural education needs to keep abreast of these changes. Access to new technology and the development of specialised architectural documentation software including BIM (Building Information Modelling), has scaffolded new building procurement methods and allowed consultant teams to work more collaboratively, efficiently and across different time zones.

As most architectural design and technology studios are based on the design and documentation of buildings using a traditional procurement method, and because of rigorous university architecture course accreditation requirements in Australia, unless they have a part time position working in an architectural office, it is difficult for students to have an authentic 'real-world' collaborative learning experience whilst they are studying at university.

It is no longer acceptable for today's design studio to consist merely of banks of desks and chairs with pin-boards and whiteboards or chalkboards. While students still create paper and cardboard working models by hand to explore form as a part of their design process, because many are modelling their designs using BIM or similar computer software, they are able to produce a high end and realistic scaled 3D physical models with relative ease at the end of the design process. As a minimum standard therefore, architectural design studios in Australia need access to workshop facilities to assist students in making 3D models. In addition to this, many students now create animations, fly-throughs and/or animated movies of their design proposals - all of which can only be submitted and viewed in digital format. Studios therefore need access to mobile computers, data projectors and image projectors as a minimum.

It is not possible to effectively keep operating design studios the same way that they have for the past two hundred years given the injection of high-end technology and personal mobile Wi-Fi enabled devices. Pedagogical approaches and learning styles have to adapt to these new opportunities for virtual design and collaboration environments for education.

\section{ACKNOWLEDGMENTS}

The author gratefully acknowledges the feedback provided by Queensland University of Technology's architecture students who participated in this study, and the ongoing support and contribution provided by her $\mathrm{PhD}$ Supervisors, Professor Jill Franz, Professor Sue Savage and Associate Professor Philip Crowther. 


\section{REFERENCES}

Alexander, B. (2004). Going nomadic: mobile learning in higher education. Educause Review, 39(5), 28.

Barr, R. B., \& Tagg, J. (1995). From Teaching to Learning: A New Paradigm for Undergraduate Education. Change, (6). 12.

Beichner, R. J., \& Saul, J. M. (2003). Introduction to the SCALE-UP (student-centered activities for large enrollment undergraduate programs) project. Proceedings of the International School of Physics "Enrico Fermi,',Varenna, Italy.

Bonwell, C. C., \& Eison, J. A. (1991). Active learning : creating excitement in the classroom. Washington, DC : School of Education and Human Development, George Washington University, 1991.

Cuff, D. (1991). Architecture : the story of practice. Cambridge, Mass. : MIT Press, c1991.

Dugdale, S., Torino, R., \& Felix, E. (2009). A Case Study in Master Planning the Learning Landscape Hub Concepts for the University at Buffalo. EDUCAUSE Quarterly, 32(1).

Duggan, F. (2004). The Changing Nature of the Studio as an Educational Setting. Transactions, 1(2), 70-76.Retrieved from http://dx.doi.org/10.11120/tran.2004.01020070

Harrison, A. (2006). Working to learn, learning to work: Design in educational transformation. Paper presented at the Fourth Annual Founder's Lecture. London: Royal College of Physicians.

Harrison, A., \& Hutton, L. (2014). Design for the changing educational landscape. London: Routledge. Ito, M., Gutiérrez, K., Livingstone, S., Penuel, B., Rhodes, J., Salen, K., Watkins, S. C. (2013). Connected learning: An agenda for research and design. Digital Media and Learning Research Hub.

Jamieson, P. (2009). The serious matter of informal learning: from the development of learning spaces to a broader understanding of the entire campus as a learning space. Planning For Higher Education, (2), 18.

Jamieson, P., Fisher, K., Gilding, T., Taylor, P.G. \& Trevitt, A.C.F. (2000). Place and Space in the Design of New Learning Environments. Higher Education Research and Development, 19(2), 221.

Koch, A., Schwennsen, K., Dutton, T., \& Smith, D. (2002). The Redesign of Studio Culture: A Report of the AIAS Studio Culture Task Force. Studio Culture Task Force, The American Institute of Architecture Students-AIAS, Washington, DC, USA.

Kostof, S. (1977). The Architect. New York: Oxford University Press.

Mewburn, I. (2011). Lost in translation: Reconsidering reflective practice and design studio pedagogy. Arts And Humanities In Higher Education, 11(4), 363-379. Retrieved from http://dx.doi.org/10.1177/1474022210393912

Neary, M., Harrison, A., Crelin, G., Parekh, N., Saunders, G., Duggan, F., et al. (2010). Learning landscapes in higher education (pp. 29). Lincoln: University of Lincoln.

Nussbaum-Beach, S., \& Hall, L. R. (2012). The connected educator: Learning and leading in a digital age. Solution Tree Press.

Oblinger, D. (2005). Leading the transition from classrooms to learning spaces. EDUCAUSE Quarterly, 1(7-12).

Osborne, L., Franz, J., Savage, S., \& Crowther, P. (2011). Dichotomy in the design studio: Adapting to new blended learning environments. ICERI2011 Proceedings, 5579-5588.

Osborne, L., Franz, J., Savage, S., \& Crowther, P. (2012). Dichotomy in the design studio 2.0: Adapting to new blended learning environments The Fourth Asian Conference on Education 2012 (pp. 1,557). Osaka, Japan. From http://iafor.org/ace2012.html

Schön, D. (1983). The reflective practitioner. New York: Basic Books.

Shreeve, A. (2012). The way we were? Signature pedagogies under threat. The 1st International Symposium for Design Education Researchers DRS/Cumulus Conference, Paris, France, May 2011

Shulman, L. (2005). Signature pedagogies in the professions. Daedalus, 134(3), 52-59. Retrieved from http://dx.doi.org/10.1162/0011526054622015

TEFMA: Tertiary Education Facilities Management Association (2009). Space Planning Guideline 3rd edition. Sydney: TEFMA Publication. 
Temple, P. (2007). Learning spaces for the 21 st century: a review of the literature.

What is connected learning? Connected learning. (2014, January). Retrieved from http://connectedlearning.tv/what-is-connected-learning

Worthington, J. (2001). Accommodating change - Emerging real estate strategies. Journal Of Corporate Real Estate, 3(1), 81-95.

\section{Lindy Osborne \\ School of Design \\ Creative Industries Faculty \\ Queensland University of Technology}

